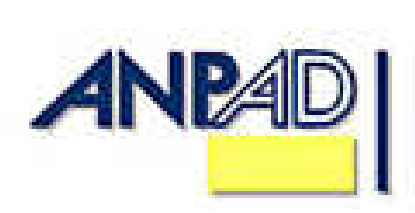

Disponível em

http://www.anpad.org.br/rac

RAC, Curitiba, v. 13, n. 3, art. 4, p. 410-429, Jul./Ago. 2009

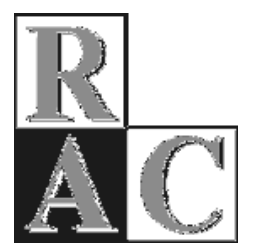

\title{
E Agora, o que Fazer com Essa Tecnologia? Um Estudo Multicaso sobre as Possibilidades de Transferência de Tecnologia na USP-RP
}

Gee, What Should I Do with This Tecnology? A Multicase Study about the Possibilities of Technology Transfer at USP-RP

Élcio Eduardo de Paula Santana * Doutorando em Administração pela UFPR. Professor do Departamento de Administração na UFG/CAC, Catalão/GO, Brasil.

Geciane Silveira Porto Doutora pela USP. Professora na FEA-RP/USP, Ribeirão Preto/SP, Brasil.

\footnotetext{
* Endereço: Élcio Eduardo de Paula Santana

UFG - Departamento de Administração, Avenida Dr. Lamartine Pinto de Avelar, 1120, Setor Universitário, Catalão/GO, 75705-220. E-mail: elcio1978@yahoo.com.br
}

Copyright @ 2009 RAC. Todos os direitos, inclusive de tradução, são reservados. É permitido citar parte de artigos sem autorização prévia desde que seja identificada a fonte. 


\section{RESUMO}

Este estudo verificou as possibilidades de transferência de tecnologia do Departamento de Física e Matemática, da Faculdade de Medicina e da Faculdade de Odontologia, instalados no campus da USP em Ribeirão Preto, para o setor de equipamentos médicos, hospitalares e odontológicos [EMHO]. O método utilizado foi o estudo de multicasos, em que se pesquisou as unidades universitárias citadas, além de cinco empresas da região da mesma cidade que integram o referido setor. $\mathrm{O}$ foco da pesquisa recaiu sobre as entidades universitárias, mas também foram obtidas informações junto ao meio empresarial para que se pudesse extrair uma amostra do pensamento tanto dessa classe quanto da acadêmica, no que se refere à transferência de tecnologia [TT]. Identificou-se 178 linhas de pesquisa (24 potencialmente aplicáveis no setor de EMHO) e 58 tecnologias desenvolvidas pela universidade (1 atraiu os empresários). Assim, verificou-se a existência de potencialidade de TT entre as entidades estudadas, porém, reflexões foram feitas a respeito da (1) burocracia universitária; (2) processo de patenteamento das tecnologias; (3) posicionamento da USP no mercado de venda de tecnologias; (4) razões pelas quais a academia (não) quer a interação universidade-empresa; e (5) comportamento passivo das empresas pesquisadas no processo cooperação.

Palavras-chave: tecnologia; transferência de tecnologia; cooperação universidade-empresa; setor de equipamentos médicos, hospitalares e odontológicos [EMHO].

\section{ABSTRACT}

This paper has verified the possibilities of technology transfer from the Department of Physics and Mathematics, the Medical School and the Dentistry School, located in the campus of USP in Ribeirão Preto, to the medical, hospital and odontologic equipment [MHOE] industry. The method applied was the multicase study, in which the university units were studied, as well as five companies in the vicinity of the same city which take part in the aforementioned industry. The focus of the research laid in the university entities, however, data was also collected with the companies' executives, in order to gather a sample of the thinking of this class of professional as well as of the academicians, on what concerns to the technology transfer [TT]. 178 lines of research were identified ( 24 potentially applicable in the MHOE industry), and 58 technologies developed by the university ( 1 drawn the attention of the executives). Thus, it has been verified the presence of potentiality of TT between the studied entities, but reflections were made on the (1) university bureaucracy; (2) the technology patenting process; (3) the USP's positioning on the technology selling marketing; (4) the reasons why the academy (don't) want the university-industry interaction; and (5) the passive behavior of the researched companies on the cooperation process.

Key words: technology; technology transfer; university-industry interaction; medical, hospital and dental equipment industry [MHDE]. 


\section{INTRODUÇÃO}

O campus de Ribeirão Preto da Universidade de São Paulo tem suas pesquisas fortemente direcionadas para a área da saúde. Conforme destacou Porto (2004), várias pesquisas são realizadas nas áreas básicas e têm enorme potencial de desenvolvimento, como aquelas empreendidas para o desenvolvimento de soros, vacinas e próteses. Unidades como as faculdades de medicina (FMRP) e de odontologia (FORP) e o Departamento de Física e Matemática [DFM] - integrante da Faculdade de Filosofia, Ciências e Letras [FFCLRP] - possuem estruturas significativas para a prática da pesquisa na área da saúde. Tais unidades dispõem de diversos laboratórios, além de possuírem uma produção científica bastante significativa, conforme atesta a Tabela 1, que também traz informações sobre outras unidades da universidade que desenvolvem pesquisas nessa área.

Tabela 1: Número de Laboratórios e Produção Científica da USP em Ribeirão Preto

\begin{tabular}{|c|c|c|c|c|c|}
\hline \multirow{3}{*}{ Centros } & \multirow{3}{*}{$\begin{array}{c}\text { Número de } \\
\text { laboratórios (2004) }\end{array}$} & \multicolumn{4}{|c|}{ Produção Científica (2006) } \\
\hline & & \multicolumn{2}{|c|}{ Publicações em periódicos e livros } & \multicolumn{2}{|c|}{$\begin{array}{c}\text { Publicações em anais de } \\
\text { congressos }\end{array}$} \\
\hline & & Brasil & Exterior & Brasil & Exterior \\
\hline EERP $^{(1)}$ & 12 & 191 & 34 & 310 & 75 \\
\hline FCFRP $^{(2)}$ & 50 & 60 & 140 & 261 & 76 \\
\hline FFCLRP $^{(3)}$ & $65^{*}$ & 147 & 185 & 408 & 104 \\
\hline $\mathrm{FMRP}^{(4)}$ & não divulgado & 327 & 429 & 573 & 260 \\
\hline FORP $^{(5)}$ & 36 & 35 & 79 & 299 & 34 \\
\hline
\end{tabular}

Fontes: Anuário Estatístico (2008a, b) e entrevistas realizadas às faculdades (EERP, FCFRP, FFCLRP, FMRP, FORP).

* Incluindo apenas os laboratórios dos departamentos de Física e Matemática, Química e Biologia.

Acredita-se que os números expostos na Tabela 1, por si sós, são representativos da capacidade de pesquisa que tais unidades possuem. Contudo reconhece-se uma limitação na exposição dessa informação pela ausência de dados comparativos com o que se produz, tanto no Estado de São Paulo quanto no Brasil; o autor deste trabalho esclarece que não conseguiu encontrar tal tipo de informação.

Todavia, convém ressaltar que a USP é uma das duas únicas universidades brasileiras que estão classificadas entre as 200 melhores universidades do mundo, ocupando o $175^{\circ}$ lugar (a outra instituição é a Unicamp, que detém o $177^{\circ}$ posto), segundo a quarta edição do ranking anual feito pelo Higher Education Supplement, do jornal britânico The Times (Marques, 2007). A mesma publicação, reproduzindo palavras da reitora da USP, Suely Vilela, ainda aponta que tal desempenho é consequiência da competência dos recursos humanos, assim como da autonomia didático-financeira que é destinada às universidades mantidas pelo governo estadual paulista.

Diante de tais fatos, acreditou-se ser pertinente o desenvolvimento de um trabalho que tivesse como foco a possibilidade da participação da universidade no processo de transferência de tecnologia para empresas pertencentes ao complexo da saúde. Contudo, decidiu-se destacar algumas unidades universitárias (DFM, FMRP e FORP) e um dos setores que compõem esse complexo, o setor de Equipamentos Médicos, Hospitalares e Odontológicos [EMHO] pois não seria viável analisar em um único trabalho todas as unidades universitárias que poderiam transferir tecnologias para todos os setores do complexo da saúde.

Além disso, havia uma expectativa elevada quanto à existência de condições favoráveis para a prática de transferência de tecnologia dessas três unidades universitárias para as empresas do setor de 
EMHO, em razão da proximidade física com a universidade, assim como por possuir convergência de interesse com os grupos de pesquisa universitários.

Faz-se necessário justificar a escolha de pesquisar instâncias de níveis diferentes, ou seja, um departamento e duas faculdades. O DFM é parte integrante da Faculdade de Filosofia, Ciências e Letras [FFCLRP], unidade que não congrega (fora o departamento citado) nenhuma outra entidade produtora de tecnologia aplicável ao setor de EMHO. Apesar desse fato relativo ao DFM - ser um departamento, diferentemente dos outros objetos de pesquisa, que são faculdades - optou-se por incluí-lo na pesquisa, dada a relevância de sua atuação, e também por acreditar que os diferentes níveis de análise não comprometeriam o objetivo da investigação.

Escolheu-se delimitar esse estudo à região Ribeirão Preto, pois além da respeitável estrutura acadêmica instalada com pesquisas direcionadas à área da saúde, há grande aglomeração de organizações pertencentes à indústria de EMHO nessa cidade, uma vez que há quarenta e sete empresas instaladas nesse município, segundo o Relatório Anual de Informações Sociais [RAIS], referente ao ano de 2005 (Ministério do Trabalho e Emprego [MTE], 2008). Tal número a coloca em segundo lugar entre aquelas cidades do Estado de São Paulo que mais sediam empresas do referido setor. A mesma base de dados ainda aponta que, nesse Estado, a cidade de São Paulo é a cidade que mais possui empresas do setor (205), Campinas é a terceira (20), e Piracicaba (13) e Rio Claro (13) vêm na sequiência. No total, o Estado de São Paulo possui 497 empresas pertencentes a essa indústria.

Demonstrada a importância do setor de EMHO em Ribeirão Preto perante o Estado de São Paulo, é relevante destacar a pertinência da referida unidade da federação quando comparado ao Brasil, como um todo, na indústria em análise. Por meio da verificação de uma nova base dados, a Pesquisa Industrial Empresa [PIA] 2005 (Instituto Brasileiro de Geografia e Estatística [IBGE], 2007), é possível afirmar que São Paulo tem cerca de 56\% das empresas do setor instaladas no país, e a receita total de suas empresas respondem a pouco mais de $54 \%$ do faturamento nacional. A Tabela 2, que é apresentada na seqüência, expõe os números absolutos.

\section{Tabela 2: Número de Empresas e Receita Total do Setor de EMHO no Brasil e em São Paulo}

\begin{tabular}{lcc}
\hline & Brasil & São Paulo \\
Número de empresas & 692 & 386 \\
Receita Total* & $4.235,40$ & $4.108,30$ \\
\hline *R\$1 milhão. & & \\
Fonte: IBGE (2007, pp. 55, 195). & &
\end{tabular}

Deve-se salientar que existe uma diferença entre a PIA 2005 (IBGE, 2007) e a RAIS 2005 (MTE, 2008) quanto ao número de empresas existentes no Estado de São Paulo (386 versus 497, respectivamente). Conjetura-se que tal diferença deva ocorrer em virtude de distintas classificações das empresas quanto ao setor em que elas estão alocadas.

Deve-se ressaltar que o setor de EMHO apresenta desafios interessantes para os pesquisadores universitários que desejam entendê-lo e colaborar para o seu desenvolvimento. Poucos trabalhos acadêmicos foram desenvolvidos sobre ele; por isso existe a necessidade de estudos que busquem compreender a sua dinâmica, particularmente no que concerne à transferência de tecnologia da universidade para a empresa, pois há uma lacuna a ser preenchida nesse aspecto.

Alguns dados adicionais ajudam a compreender a dimensão do setor de EMHO. Segundo a Associação Brasileira da Indústria de Artigos e Equipamentos Médicos, Odontológicos, Hospitalares e de Laboratórios e o Sindicato da Indústria de Artigos e Equipamentos Odontológicos, Médicos e Hospitalares do Estado de São Paulo [ABIMO/SINAEMO] (2008) o referido setor movimentou um pouco mais de $\mathrm{R} \$ 6,728$ bilhões no país, no ano de 2006 no Brasil. Em todo o mundo, conforme documento do Departamento do Comércio dos Estados Unidos (como citado em Gutierrez \& 
Alexandre, 2004), estima-se que o setor movimente cerca de US\$ 153 bilhões por ano. Além disso, Frost e Sullivan (2005) apontam que o setor apresenta uma taxa de crescimento anual composta de 9\% entre 1999 e 2004, que é uma taxa elevada quando comparada com os demais setores.

É também relevante destacar o impacto que as transações nessa indústria geram na balança comercial brasileira. De acordo com a ABIMO/SINAEMO (2008), em 2006 o Brasil importou aproximadamente US\$1,591 bilhão, enquanto as exportações totalizaram somente cerca de US\$ 442 milhões, gerando assim um considerável déficit de aproximadamente de US\$1,149 bilhão.

A importância do estudo da inovação para as empresas do setor de EMHO pode ser depreendida a partir do comentário feito por Tidd, Bessant e Pavitt (1997, como citado em Francis \& Bessant, no prelo): "pesquisas gerenciais sugerem que firmas inovadoras - aquelas as quais são capazes de usar a inovação para diferenciar seus produtos e serviços da competição - são, na média, duas vezes mais lucrativas que as outras firmas" (p. 806), ou seja, quanto mais capacitadas para a inovação forem essas empresas, mais chances de sucesso nos seus negócios elas terão.

Então, um fator que pode propiciar melhores condições para o surgimento de inovações e desenvolvimento de tecnologia no setor de EMHO é a interação das universidades com as empresas que o compõem, bem como com os profissionais da mesma área. Deve-se destacar que, nas instituições universitárias, as empresas podem encontrar pessoas com capacidades específicas e altamente treinadas, o que pode ser de grande valia para a execução de seu processo inovativo. Como afirmou Plonski (1999) - em artigo que analisa a cooperação universidade-empresa [U-E] sob a ótica da gestão - "pessoas de elevada competência são o cerne da inovação" (p. 10).

Essa cooperação da universidade com as empresas do setor de EMHO pode ser realizada de várias formas; uma delas é o deslocamento da tecnologia desenvolvida por essa entidade para aquela, ou seja, a transferência de tecnologia. Tal ação é muito pertinente, devido ao fato de a empresa obter conhecimentos que lhe propiciem condições para inovar. Além disso, baseado na prática de Pró-Reitor de Pesquisa da USP por dois anos, Chaimovich (1999) destacou, em um artigo que enfoca o diálogo entre a universidade e a empresa, que "o elo final da incorporação de valor ao produto consiste em uma inovação na linha de produção" (p. 20) que, no caso da universidade, só pode acontecer, caso a tecnologia que ela desenvolveu seja transferida para uma empresa, visto que suas atividades centrais giram em torno de ensino, pesquisa e extensão, não envolvendo a manufatura de produtos.

As empresas brasileiras ainda não têm a cultura de utilizar as universidades e os institutos de pesquisa como fontes de tecnologia. Segundo o Instituto Brasileiro de Geografia e Estatística [IBGE] (2002), as universidades e os institutos de pesquisa aparecem em décimo lugar, em nível de importância como fonte de informações para inovação, quando se considera o setor 33 - que é o setor referente à fabricação de equipamentos de instrumentação médico-hospitalares, instrumentos de precisão e ópticos, equipamentos para automação industrial, cronômetros e relógios. Tal especificação (setor 33) é fornecida pela Classificação Nacional de Atividades Econômicas [CNAE] (2004).

Por outro lado, o relatório Science, Technology and Industry Outlook, do ano de 2002, da Organização para Cooperação e Desenvolvimento Econômico [OECD] em 2004, apontou o financiamento por parte das empresas para pesquisas em universidades e laboratórios públicos como uma variável pertinente às estratégias empresariais atuais. Tal fato ocorre, segundo a OECD (2004), porque as empresas se viram impedidas de manter a excelência em todas as áreas da inovação, devido ao aumento considerável do conhecimento científico e tecnológico que foram transferidos para os produtos e serviços de um amplo número de setores de atuação. Vale a ressalva de que essa realidade foi observada nos países desenvolvidos, especialmente na Europa.

Diante desse contexto, observa-se a importância e a conseqüente necessidade do estudo da inovação no setor de EMHO, para que se venha a apresentar um panorama da transferência de tecnologia de uma universidade para as suas empresas e para que se tenha mais um documento suscetível de ser analisado e utilizado pelas entidades atuantes nessa indústria. Especialmente a transferência de tecnologia de universidades para empresas demonstra ser uma alternativa viável e consistente, pois 
ambas as entidades se concentrariam em suas atividades centrais, o que propiciaria condições para a maximização de suas forças. Esta análise pode ainda ajudar a universidade a adequar sua estrutura e seus recursos, possibilitando que ela coopere com as empresas desse setor de maneira mais incisiva.

Visto isso, estabeleceu-se o seguinte objetivo para a realização desta pesquisa: identificar a potencialidade de transferência de tecnologia do Departamento de Física e Matemática, da Faculdade de Medicina e da Faculdade de Odontologia da USP - campus de Ribeirão Preto - para o setor de equipamentos médicos, hospitalares e odontológicos.

\section{REFERENCIAL TEÓRICO}

O referencial teórico deste artigo versa sobre a cooperação universidade-empresa e a transferência de tecnologia, temas que embasarão a discussão dos resultados, a ser realizada em seção posterior deste trabalho.

\section{Cooperação Universidade-Empresa}

A cooperação universidade-empresa é o estabelecimento de relações entre a universidade e a empresa, de maneira que as atividades impetradas promovam uma sinergia entre as organizações, tornando-as mais competitivas em seus respectivos campos de ação. Tais relações podem variar quanto ao nível de formalidade, profundidade e modalidade. Uma definição, bastante extensa e completa sobre o que é a cooperação U-E, e que foi adotada como referência para este trabalho, foi apresentada por Plonski (1992), o qual propõe que ela é

um modelo de arranjo interinstitucional de organizações de natureza fundamentalmente distinta, que podem ter finalidades diferentes e adotar formatos bastante diversos. Inclui-se neste conceito desde interações tênues e pouco comprometedoras, como o oferecimento de estágios profissionalizantes, até vinculações intensas e extensas, como os grandes programas de pesquisa cooperativa, em que chega a ocorrer repartição dos reditos resultantes da comercialização dos seus resultados (p. VIII).

Dessa forma, a opção estratégica pela cooperação universidade-empresa se faz interessante para empresas que enfrentam algum tipo de dificuldade tecnológica, pois o "potencial de desenvolvimento a ser conquistado com a adoção de tecnologias já dominadas ou ainda por serem desenvolvidas pelas universidades e institutos de pesquisa é grande e com custos significativamente menores para as empresas" (Porto, 2000, p. 50).

Por sua vez, Metcalfe (2003, p. 113) destaca o papel das empresas no processo de cooperação com a universidade, apontando que poucas delas têm condições de inovar isoladamente; além disso, ele expõe que "a firma é única, como uma organização, em seu papel de ter de adquirir e combinar vários tipos diferentes de conhecimento e de colocá-los em um esforço prático" [tradução nossa].

Já de acordo com Vedovello (1998), a cooperação entre universidades e empresas em campos de interesses que sobrepõem a ciência e a tecnologia, gera benefícios tanto para os participantes diretos da interação quanto, até mesmo, do país, pois promove melhoria na competitividade de sua indústria.

Por sua vez, Etzkowitz e Leydesdorff (1997a, p. 3) apontam que

as mudanças na economia levaram a mudanças em outras partes da estrutura do conhecimento (...) sob essas condições de mudança, com universidades sendo cada vez mais vistas como atores em sistemas de inovações regional e nacional, limites distintos estão sendo eliminados e substituídos por uma rede de teias. 
Esses limites que existem entre as universidades e empresas se devem principalmente aos objetivos distintos inerentes a cada entidade, como a industrialização, por parte dessas e a pesquisa básica, por parte daquelas (Nuchera, Serrano, \& Morrote, 2002). Contudo, pelo fato de se vislumbrar uma ajuda mútua para o desenvolvimento de produtos e serviços, a interação das instituições se torna uma possibilidade real. Além disso, Santoro e Betts (2002) citam que outra vantagem dessa relação é o fato de não haver os conflitos de interesse comercial que geralmente assolam as cooperações entre empresas.

Santoro e Betts (2002, p. 42) também postulam que "parcerias universidade-empresa oferecem uma alternativa potencialmente poderosa às colaborações entre firmas, que empresas de sucesso rotineiramente executam no ambiente competitivo de hoje" [tradução nossa]. Mora-Valentin, Montoro-Sanchez e Guerras-Martins $(2004$, p. 1) adicionam que "a cooperação une a pesquisa básica à pesquisa aplicada, resultando no desenvolvimento da economia e do potencial tecnológico dos parceiros envolvidos".

Santoro e Betts (2002) ainda afirmam que, no passado, diferentemente de hoje, as relações entre universidades e empresas se baseavam somente no patrocínio dessas com relação às pesquisas daquelas. Eles ainda apontam que a economia baseada no conhecimento trouxe a cooperação universidade-empresa do nível do patrocínio para o da parceria: sendo que a universidade pode ser um parceiro que traz expertise, conhecimento e recursos que não estão disponíveis na comunidade empresarial.

Contudo, para que tanto a universidade quanto a empresa tenham as suas necessidades atendidas, é postulado por Fracasso e Santos (1992, p. 63) que as políticas universitárias têm de ser "de tal natureza que não possam ser impeditivas da existência do modelo, que deverá ser de tal modo flexível que permita formas diferenciadas dentro da mesma universidade, uma vez que nela coexistem diferentes paradigmas de ciência que devem ser preservados".

Convém ainda ser ressaltado o papel do governo no processo de interação, já enfatizado por Sábato e Botana, em seu renomado Triângulo de Sábato, o qual propõe que o governo atue decisivamente na cooperação U-E, por meio da geração de incentivos, tanto de ordem financeira quanto estratégica (Plonski, 1998).

Ainda com relação à atuação governamental, deve-se destacar outro modelo, denominado "Hélice Tripla" (Etzkowitz \& Leydesdorff, 1997b): de acordo com os autores, o modelo tem o seu ponto inicial nas formas de diferenciações institucionais entre as universidades, indústrias e governos, que sofrem adições advindas da perspectiva evolucionária, a qual expõe que o fator humano "reflexivamente remolda estas instituições. O modelo, dessa forma, leva em consideração a expansão do papel do setor do conhecimento em relação à infra-estrutura política e econômica da sociedade como um todo" (p. 155).

Os autores da Hélice Tripla também destacam os cortes de verbas públicas para as universidades, o que explicita a necessidade de novos formatos organizacionais que possibilitam o melhor desempenho dessas instituições. Tais formatos são moldados a partir de interações com outros setores da sociedade, como o governo e as empresas, propiciando também novas possibilidades para esses agentes. Essas interações geram a necessidade de surgimento de mecanismos de acoplamento, que podem ser exemplificados, dentre outras formas, nas incubadoras de empresas. Destarte, esse modelo busca propor uma resposta à necessidade de mecanismos de transição para essas complexas redes de ação recíproca.

Entretanto, apesar de todas as benesses expostas, que advém da cooperação U-E, Porto (2006, p. 12) destaca que

a cooperação não é uma relação tranqüila, devido às diferenças estruturais e de objetivos que cada organização possui, o que pode gerar percepções e expectativas contraditórias sobre o tema. Nesse sentido, a fim de se estabelecer um ambiente minimamente adequado ao trabalho cooperativo, deverão ser estabelecidos os objetivos de cada uma das partes envolvidas, bem como o objetivo que 
o projeto como um todo pretende realizar. A falta de definição de prioridades institucionais e de objetivos claros tem restringido a cooperação das iniciativas pessoais, o que resulta em programas caóticos, cujos resultados são instáveis, tornando a cooperação um produto da sorte, vinculado ao talento das pessoas que dela participam.

Além disso, Segatto-Mendes e Sbragia (2002), Segatto (1996), Porto (2000) e Alvim (1998), apresentam uma série de barreiras que ou torna a cooperação uma ação impraticável, ou então dificulta a sua operacionalização. No concernente à academia, destaca-se com maior ênfase a prioridade de foco à ciência básica, o tempo que se necessita para o desenvolvimento das atividades, a burocracia dos procedimentos administrativos, e a estrutura organizacional inadequada.

Com relação às empresas, os mesmos autores citam mais veementemente os seguintes itens: necessidade de confidencialidade, visão imediatista adotada na gestão de negócios e falta de informação do que é produzido nos centros de pesquisa etc.

Todavia, os mesmos autores, acompanhados de Santoro e Betts (2002), ressaltam alguns fatores que minimizam a existência de tais barreiras, pois proporcionam maiores facilidades para que a cooperação U-E efetivamente aconteça. No que se refere às universidades, destaque maior é ofertado à propriedade de conhecimentos essenciais para a inovação, assim como a existência de tecnologias já desenvolvidas. Já no que concerne às empresas, vale ressaltar a consideração da inovação como elemento fundamental do negócio.

Além disso, importa mencionar os fatores que contribuem para o sucesso da cooperação U-E, de acordo com Mora-Valentin et al. (2004), os quais são classificados em contextuais e organizacionais. Os primeiros referem-se às ligações cooperativas anteriores, à reputação dos parceiros e à clara definição de objetivos individuais e coletivos. Por sua vez, o segundo diz respeito ao nível de envolvimento dos parceiros na cooperação, ao processo de troca de informações e idéias entre os indivíduos que participam da cooperação, e a confiança mútua entre os parceiros.

Por fim, salienta-se que, de acordo com Santoro e Chakrabarti (2002), a cooperação entre empresas e universidades pode ser classificada de quatro maneiras distintas: suporte à pesquisa, a pesquisa cooperativa, a transferência de conhecimento e a transferência de tecnologia. Como o tema central deste artigo é o último formato de interação citado, ele será destacado individualmente em um novo tópico, a seguir.

\section{Transferência de Tecnologia}

Natal e Vivés (1998) mencionam duas formas de uma organização obter tecnologia de ponta: autodesenvolvimento ou aquisição. Em algumas situações, desenvolver a sua própria tecnologia pode não ser a opção mais apropriada para a organização. Tal fato remete, então, à necessidade de compra da tecnologia de que se necessita, advinda de um dado fornecedor; uma das formas de se adquirir esse bem é a transferência de tecnologia.

Visto isso, defini-se a transferência de tecnologia como "a movimentação da inovação tecnológica de uma organização de P\&D para uma organização receptora" (Rogers, Takegami, \& Yin, 2001, p. 254), como, por exemplo, uma companhia privada. Jain e Triandis (1997, p. 200) corroboram tal definição, afirmando que a transferência de tecnologia é "o processo pelo qual ciência e tecnologia são transferidas de um indivíduo ou grupo para outro, que incorpora este novo conhecimento dentro de seu modo de fazer as coisas". Situando a transferência de tecnologia no contexto da cooperação U-E, Santoro e Chakrabarti (2002) afirmam que a empresa oferta à universidade o conhecimento em determinado campo do conhecimento, no concernente à sua relação com o mercado; por sua vez, a universidade desenvolve conhecimento, de ordem básica e técnica. A interação dessas duas dimensões objetiva a geração de tecnologias comercializáveis no mercado.

No tocante às entidades integrantes do processo de transferência de tecnologia, Siegel, Waldman e Link (2003) destacam os cientistas universitários, os escritórios de transferência de tecnologia [ETT] e 
o empreendedor empresarial como os principais stakeholders (partes interessadas) desse processo envolvendo universidades e empresas. Vale destacar a quase inexistência dos ETTs no Brasil, a exceção de alguns casos notórios como o ETT da PUC-RS e a INOVA, da Unicamp. No caso da USP, a recém criada Agência USP de Inovação [USPInovação] se propõe a cumprir esse papel (antes desempenhado por um órgão chamado Grupo de Assessoramento ao Desenvolvimento de Inventos [GADI] incorporado pela citada agência).

Assim, para que a transferência de tecnologia entre os citados stakeholders possa ser viabilizada, seis meios são apontados por Reisman (2004): troca de informações, como publicações em periódicos; vendas, que podem ser, por exemplo, de equipamentos; acordos de cooperação, como a co-produção, a co-pesquisa e o co-planejamento; licenciamento; franquia; e joint-venture.

Dentre esses meios, o licenciamento merece um destaque especial nessa ação de transferência de tecnologia da universidade para a empresa. De acordo com Anon (1995, como citado em Rogers et al., 2001, p. 255), o licenciamento "é a outorga de permissão ou direitos de fazer, usar e/ou vender certo produto, desenho ou processo". Usualmente são pagos royalties pelo recebedor da tecnologia para o emissor dela, que se constitui em uma taxa de licenciamento. Todavia, deve ser ressaltado que, antes da transferência da tecnologia, esta teve os seus direitos de criação resguardados pelos seus desenvolvedores, gerando uma propriedade intelectual.

A propriedade intelectual, de acordo com a World Intellectual Property Organization [WIPO] (n.d), "refere-se às criações da mente, trabalhos literários e artísticos, símbolos, nomes, imagens e desenhos usados no comércio", que podem ser divididas em 1) propriedade industrial, que envolve invenções (patentes), marcas-registradas, desenhos industriais e indicações geográficas de fonte; e 2) direitos autorais (copyright), que se refere a trabalhos artísticos e literários, como romances, poemas e peças, filmes, trabalhos musicais, trabalhos artísticos, como desenhos, pinturas, fotografias e esculturas e desenhos arquitetônicos. Para finalizar, é interessante notar uma observação de Siegel, Waldman, Atwater e Link (2003), direcionada aos cientistas e administradores da universidade, em que afirmam a importância de se perceber que licenciamentos, royalties e patentes não são solução de todos os problemas, destacando que também se fazem necessários os relacionamentos pessoais e as redes de contatos, para o bom desenvolvimento de uma cooperação U-E e uma decorrente ação de transferência de tecnologia.

\section{ASPECTOS METODOLÓGICOS}

Realizou-se uma pesquisa qualitativa (Richardson, 1999), com abordagem exploratória, empregando o estudo de caso como técnica de pesquisa (Yin, 2001). Foram coletados tanto dados primários quanto secundários.

O processo de coleta dos dados primários iniciou-se por meio de contatos via telefone e e-mail com os pesquisadores e executivos selecionados para serem os respondentes da pesquisa; nesse momento, efetuou-se o agendamento das entrevistas. Então, foram realizadas as entrevistas, quando se utilizou um gravador para o registro das informações. Também foi utilizada a comunicação via e-mail para sanar dúvidas geradas após as análises das entrevistas, assim como para obter algumas informações específicas adicionais. Foi utilizado um roteiro semi-estruturado que gerou respostas abertas, constituindo-se assim em vários estudos de casos.

Por sua vez, a coleta dos dados secundários se deu por meio da busca de informações em documentos organizacionais, na internet, em revistas e em jornais. Como tática de análise de dados, adotou-se a análise de conteúdo, conforme preceitos citados por Richardson (1999). Primeiramente, selecionou-se o material a ser estudado (supracitado). Então, a análise, per se, não estabeleceu categorias pré-fixadas - tais segmentações emergiram iterativas seções de leitura do texto. A chave 
para a identificação dessas categorias foram frases que recorrentemente eram citadas pelos entrevistados, assim como os fatos que repetidamente eram destacados nos documentos elencados.

Vale ressaltar que os dados obtidos e analisados tiveram a sua validade confirmada por dois doutores, ambos professores da USP, além da discussão impetrada entre os dois autores do artigo.

O universo da pesquisa compreendeu as faculdades de medicina e odontologia, e o Departamento de Física-Médica, instalados no campus de Ribeirão Preto-SP, da Universidade de São Paulo [USP] e cinco empresas do setor de EMHO da região de Ribeirão Preto, totalizando vinte e sete entrevistas com integrantes da universidade e cinco com representantes das empresas.

Salienta-se que a FMRP demandou uma operacionalização diferente na coleta dos dados. Em virtude de possuir catorze departamentos, era impossível identificar entrevistados que pudessem ofertar informações precisas sobre todas essas unidades. Desta forma, decidiu-se entrevistar membros de cada um desses departamentos. Contudo, no concernente à apresentação dos dados obtidos, estes serão dispostos de forma agregada, para melhor utilização do espaço disponível para a redação.

Ademais, para facilitar e tornar mais precisa a análise dos dados obtidos, decidiu-se também realizar uma pesquisa com dois componentes da Agência USPInovação, que eram integrantes do GADI (órgão absorvido pela citada agência), que puderam oferecer uma visão mais acurada de como se dá o processo de patenteamento e de licenciamento de tecnologias da universidade.

Deve ser destacado que os resultados encontrados são representativos somente para as unidades universitárias e as empresas pesquisadas, não podendo ser ampliados nem para outras universidades, nem para as demais unidades universitárias da USP-RP nem para outras empresas componentes do setor de EMHO.

\section{DESCRIÇÃo E ANÁLISE DOS RESULTADOS}

Os resultados da pesquisa são apresentados em subseções para tornar a apresentação mais explícita, pois evidencia, de forma mais contundente, os tópicos que realmente merecem consideração. Desta forma, este item será dividido em seis partes. A primeira versa sobre os números da pesquisa, relativos às linhas de pesquisa e tecnologias desenvolvidas pela universidade, e aos casos de transferência de tecnologias já realizados, tanto pela academia quanto pelo setor produtivo. Em um segundo momento, escreve-se sobre a burocracia universitária, no seu sentido vulgar, que impede a melhor realização dos processos de cooperação U-E/transferência de tecnologia. Na seqüência, postula-se a respeito da ação de patentear as tecnologias desenvolvidas. Em quarto lugar, são apresentados e discutidos os resultados acerca do posicionamento da USP no mercado de venda de tecnologias. Em seguida, expõem-se as razões pelas quais a academia (não) quer a interação universidade-empresa. Por fim, fazse menção do comportamento passivo das empresas pesquisadas no processo cooperação.

\section{Os Números da Pesquisa}

Foram identificadas 178 competências de pesquisa (linhas de pesquisa) nas três unidades analisadas. Dessas, vinte e quatro apresentam potencial para serem aplicadas nas empresas do setor de EMHO, de acordo com os entrevistados das próprias empresas.

Obteve-se o número de cinqüenta e oito tecnologias desenvolvidas (ou em desenvolvimento, no momento da pesquisa) pelas três unidades universitárias pesquisadas, sendo trinta destinadas ao setor de EMHO. Ressalta-se que, dentre essas, vinte já foram patenteadas (ou tiveram o pedido já depositado) - treze dentre aquelas voltadas ao setor de EMHO. 
Contudo o interesse das empresas pesquisadas nas referidas tecnologias foi mínimo: apenas uma dessas cinqüenta e oito tecnologias proporcionou atração imediata dos entrevistados. Apesar desse apontamento, faz-se necessário mencionar que os executivos entrevistados se mostraram propensos a utilizar as tecnologias desenvolvidas no âmbito universitário, desde que elas venham a se adequar aos objetivos de suas respectivas organizações. No concernente à transferência de tecnologia da universidade para a empresa, verificou-se a existência de poucos casos que envolvessem as unidades universitárias e as empresas pesquisadas. A universidade apresentou apenas dois processos direcionados ao setor de EMHO, entre os cinco citados ao longo da pesquisa, como destaca a Tabela 3.

Tabela 3: Casos de Tecnologias Transferidas das Unidades Universitárias Pesquisadas para Empresas do Setor Privado

\begin{tabular}{|c|c|}
\hline Aplicáveis ao setor de EMHO & Não aplicáveis ao setor de EMHO \\
\hline \multirow{2}{*}{$\begin{array}{l}\text { - Aperfeiçoamento em instrumental de fixação de } \\
\text { haste bloqueante antotelescopável em fraturas } \\
\text { diasfisárias e respectivo método de aplicação (haste } \\
\text { intramedular bloqueada): transferido para empresa não } \\
\text { identificada }\end{array}$} & $\begin{array}{l}\text { - Uso de soro látex para cicatrização de feridas } \\
\text { crônicas: transferida para empresa Pele Nova } \\
\text { Biotecnologia, gerando o produto Biocure }\end{array}$ \\
\hline & $\begin{array}{l}\text { - Disposição introduzida em escova dental monobloco } \\
\text { (Escova dental monobloco): transferida para uma spin- } \\
\text { off do próprio inventor }\end{array}$ \\
\hline $\begin{array}{l}\text { - Ceratrômetro para Lâmpada de Fenda: transferida } \\
\text { para a empresa Apramed Aparelhos Médicos }\end{array}$ & $\begin{array}{l}\text { - Disposição introduzida em escova dental } \\
\text { eletromecânica giratória: transferida para uma spin-off } \\
\text { do próprio inventor }\end{array}$ \\
\hline
\end{tabular}

Com relação às empresas pesquisadas, apenas duas das cinco apontaram a ocorrência de casos de transferência de tecnologia, a partir de universidades, de maneira formal, por meio de acordo institucional. Contudo nenhum desses acordos foi realizado com a USP-RP. Salienta-se, porém, que uma dessas empresas recebeu uma tecnologia desenvolvida por uma pessoa que é docente da USP, e integra o corpo de pesquisadores de um dos departamentos pesquisados, no campus de Ribeirão Preto; todavia esse docente é alocado em outro departamento da USP que não aqueles pesquisados, o que propiciou a essa outra unidade a determinação oficial de origem dessa tecnologia.

A outra empresa citada já participou de quatro casos de transferência de tecnologia, que não puderam ser mencionados pelo entrevistado, excetuando o último, que consistiu no desenvolvimento de um cabeçote emissor de radiação de alta freqüência, pelo Instituto de Eletrotécnica e Energia [IEE], da USP, campus de São Paulo, para compor um aparelho denominado Raio-X Panorâmico.

O baixo número de casos de transferência de tecnologia identificados torna premente o apontamento das causas dessa situação. Acredita-se, desta forma, que seja importante a identificação dos fatores que impactam, tanto positiva quanto negativamente, o processo de transferência de tecnologia, assim como na ação que pode precedê-lo, a cooperação U-E. Na sequiência, tais questões são abordadas.

\section{Burocracia Universitária}

Os dados coletados demonstraram uma propensão dos pesquisados em apontar a burocracia presente na estrutura universitária, como um dos fatores mais pertinentes à dificuldade de se desenvolver processos de transferência de tecnologia.

Foi destacado que a burocracia gera distorções no processo de cooperação, pois alguns dos integrantes da universidade, juntamente com algumas empresas, desenvolvem relações informais que 
lhes possibilitam realizar as atividades de interação desejadas, sem que a morosa estrutura universitária impeça essas ações. O problema decorrente dessa situação é que a USP não participa da divisão dos resultados dessa cooperação, fato que não pode ser aceito, visto que ela disponibiliza a estrutura para as pesquisas, além de ser a empregadora do pesquisador.

Algumas mudanças na universidade poderiam beneficiar a gestão do processo de cooperação, principalmente por meio da descentralização das decisões, além do aumento do número de pessoas envolvidas no processo. Pode-se questionar a falta de verbas para a implementação de tais mudanças, fato que talvez possa ser solucionado no momento em que os gestores da USP e dos órgão estatais que regulem o funcionamento das universidades consigam projetar retornos futuros para a universidade, advindos das empresas que viessem a participar dos vários processos de cooperação entre a universidade e a empresa, o que justificaria a alocação de mais verba para essa atividade.

Deve-se ressaltar que já existem algumas ações da universidade que denotam sua preocupação em melhorar os seus serviços, visando a uma maior agilidade para aprovação de convênios entre a universidade e as empresas, como a criação do Grupo Assessor e Convênios, órgão do Gabinete do Reitor, que se constitui em uma equipe que se reúne semanalmente para se dedicar exclusivamente à análise de processos da USP, o que torna mais ágil a aprovação dos convênios com as empresas.

Importa mencionar, como ponto de referência, que o prazo médio para a assinatura de convênios entre a USP e as empresas privadas é similar àqueles praticados pelas outras universidades públicas, o que aponta uma dificuldade maior na modificação de sua estrutura e processos, dada a rigidez existente nas regulamentações pertinentes aos órgãos públicos.

Apesar da existência de algumas ações relevantes contra a burocracia, evidenciadas anteriormente, algumas dificuldades dessa natureza são inerentes ao setor público. Um exemplo pode ser evidenciado na falta de financiamento para a elaboração de pequenos protótipos - um problema aparentemente insolúvel a curto prazo. A necessidade de tais artefatos foi justificada pelos pesquisadores pelo fato de os protótipos tornarem mais tangível o resultado do desenvolvimento da tecnologia em um produto, o que possibilitaria uma melhor visualização do empresário sobre a possível tecnologia a ser transferida para ele, o que poderia facilitar o fechamento de acordo para a execução da transferência da tecnologia.

Os pesquisadores afirmaram que a criação desse protótipo geralmente não é realizada, porque não se conseguem verbas para essa ação, visto que, não necessariamente, a pesquisa que levou ao desenvolvimento desse protótipo se caracterizou como pesquisa científica. Neste caso, não há verbas para a realização de protótipos, que poderiam ser tanto provenientes da estrutura universitária quanto dos órgãos de fomento, seja porque não podem ser incluídos no projeto fomentado, seja porque a pesquisa que os originou não se caracteriza como científica, dentro das classificações vigentes.

\section{Patenteamento}

Com relação ao processo de patenteamento, destaca-se que muitas das críticas impetradas pelos pesquisadores ao GADI (órgão responsável por essa atividade na época da pesquisa) merecem algumas considerações, especialmente as citações de que essa entidade torna o processo moroso, pois ela possui alguns indicadores que demonstram a sua eficiência e eficácia, conforme demonstram os números a seguir: mais de $95 \%$ dos pedidos de patentes realizados são deferidos pelo INPI e os pedidos depositados aumentaram de vinte e um, em 2004, para quarenta, em 2005.

Importa também postular que, em determinados processos, a demora na operacionalização dos processos de patenteamento, liderados pelo GADI, ocorria em razão do corpo exíguo de colaboradores de que o órgão dispunha, dos poucos recursos financeiros disponíveis e dos vários campi nos quais o órgão tinha que atuar concomitantemente - sem a existência de um representante em cada um deles dificuldades que já estão sendo superadas com a Agência USPInovação. 
Convém ressaltar outra melhora recentemente desenvolvida pelo GADI, que adveio da possibilidade de contratação de escritórios que realizam a redação da patente, com dispensa de licitação, ação possibilitada pela utilização dos recursos provenientes da fundação de apoio. Tal fato agilizou consideravelmente o processo, assim como o tornou mais eficiente, visto que é possível contratar escritórios especializados em redação de patentes que possuam especialistas na área do conhecimento da qual a tecnologia desenvolvida provém, o que possibilita a variação de escritório, caso a caso.

O GADI ainda argumenta em sua defesa que, em muitos casos, os docentes não contribuíam para o melhor andamento do processo de patenteamento, visto que eles não eram rápidos nos retornos das análises emitidas pela entidade, além de não enviarem os relatórios descritivos da patente para o mesmo órgão - antes das entrevistas às quais eles se submetiam juntamente com o especialista em redação de patentes (profissional contratado pelo GADI exclusivamente para essa fase do patenteamento).

Como argumento de defesa, os docentes recorrentemente expunham a sobrecarga de atividades como um fator que pode fazer com que eles atrasem alguma ação que lhes cabia no processo de transferência de tecnologia, mais precisamente, o patenteamento. Foi exposto por eles que suas funções na universidade (ensino, pesquisa e extensão) já preenchem completamente o seu tempo. Tal fato é ainda mais enfatizado, quando foi exposto uma quarta atividade docente, a administrativa, função amplamente desempenhada pelos professores/pesquisadores, especialmente por não contarem com equipes que os apóiem em tal tipo de atividade.

A justificativa ganha mais corpo quando os docentes discutem a avaliação que lhes é periodicamente imposta. Tal avaliação prioriza preponderantemente a publicação de artigos, relegando a planos inferiores as atividades/resultados pertinentes à cooperação U-E/transferência de tecnologia.

Desta forma, fica exposto que a questão relativa ao patenteamento pode não se configurar como entrave ao processo de transferência de tecnologia que se origina da estrutura universitária, e sim do agente, especificamente o docente, que deveria ser um dos elementos mais interessados no melhor desenvolvimento do processo. Contudo importa ponderar o fato de que diversos docentes culparam a estrutura universitária pela demora do processo de patenteamento, o que faz requerer investigações mais específicas sobre onde está realmente o gargalo, e como ele se configura e muda de forma.

\section{Posicionamento da USP no Mercado}

Foi mencionado pelos entrevistados, especialmente por aqueles advindos do setor empresarial, que a universidade não se prepara adequadamente para realizar atividades de transferência de tecnologia. Os respondentes versaram sobre as dificuldades em se acessar o conhecimento produzido na instituição, referência desta pesquisa, tanto no momento de verificar as tecnologias desenvolvidas/em desenvolvimento, quanto na situação em se precisa operacionalizar algum contato, por não haver caminho explicitamente delineado, que seja de conhecimento do público externo à academia.

Ademais, os entrevistados ainda expuseram as dificuldades burocráticas, já expostas no item Burocracia Universitária.

Tais fatos levam os autores do artigo a propor que a USP precisa ponderar se entre as suas prioridades está a cooperação universidade-empresa, e a partir dessa decisão disponibilizar as condições necessárias para que os seus pesquisadores possam desenvolver a matéria-prima para tais interações (as tecnologias aplicáveis aos setores industriais). Além disso, uma estrutura gerencial deveria ser ofertada para a exposição das tecnologias desenvolvidas/em desenvolvimento para possíveis investidores externos, ou seja, a USP necessita posicionar-se dentro do mercado de tecnologias: ela quer ser um player do setor ou apenas deseja produzir conhecimento e tecnologia com fim em si mesmo, somente para promover a educação de seus discentes e o desenvolvimento intelectual dos seus docentes? 
Além de conhecer a si mesma, a USP, assim como todas as demais universidades brasileiras, também devem questionar se é possível desenvolver processos cooperativos e de transferência de tecnologias no Brasil, em decorrência da regulamentação sobre a avaliação docente que limita fortemente o trabalho deles, afora a produção de artigos científicos.

Caso a opção seja por atuar ativamente no mercado de comercialização de tecnologias, acredita-se que a Agência USPInovação - assim que finalizar a sua estruturação - seja um stakeholder que a ajudará decisivamente nessa ação, agindo como escritório de transferência de tecnologia. Tal agência deverá posicionar-se de forma ainda mais intensa como a catalisadora dos processos de cooperação universidade-empresa, segurança da propriedade intelectual e transferência de tecnologia; ela pode disseminar tais conceitos, incentivar suas realizações, assessorar os procedimentos requisitados e criar mecanismos de conversação entre as partes interessadas, fato que pode contribuir até mesmo para uma melhor compreensão das necessidades e desejos de ambos os lados.

As ações citadas no parágrafo anterior permitirão que a universidade supra algumas falhas que são gritantes, no concernente à cooperação entre a academia e o setor produtivo, como a ausência de um órgão universitário que seja facilmente identificado e acessado pelos empresários, para que assim iniciem conversações com a universidade no sentido de promover algum tipo de interação.

Caso a Agênica USPInovação se posicione realmente dessa forma, ela poderá permitir que a academia e o setor produtivo se moldem de maneira que tenham condições de se complementarem, gerando uma associação virtuosa. Ela também deve amenizar o impacto que a burocracia universitária tem, principalmente, sobre a aprovação dos convênios de cooperação com as empresas, visto que dispõe de mais recursos, tanto financeiros quanto humanos, que seu órgão antecessor (GADI).

\section{Qual a Razão da Academia (Não) Querer a Interação Universidade-empresa?}

A pesquisa evidenciou a existência de uma pequena parcela dos pesquisadores universitários que não se posicionaram a favor da cooperação com empresas e da transferência de tecnologias. Acredita-se que isso tenha acontecido porque esses docentes não conseguem visualizar a potencialidade de geração de tecnologias a partir de suas atividades de pesquisa, especialmente para o setor de EMHO; a autoridade para tal justificativa advém da experiência dos pesquisadores no concernente a tal tipo de investigação - a postura de quem é, por definição, radicalmente contra a cooperação U-E/transferência de tecnologia é bem peculiar e explícita. Por isso, conjetura-se que não foram encontrados casos de pesquisadores que sejam refratários convictos à cooperação com as empresas.

Por outro lado, verificou-se a existência de uma característica similar em grande parte das unidades universitárias pesquisadas que são receptivas à idéia da cooperação universidade-empresa: a possibilidade de obtenção de recursos financeiros para a universidade, em decorrência da necessidade de investimentos que as unidades pesquisadas afirmaram necessitar para o melhor desenvolvimento de suas atividades.

Além disso, apesar de não terem sido explicita e recorrentemente citados nas entrevistas, pôde-se depreender que dois fatores são pertinentes ao pensamento dos docentes dessas unidades mais propensas à cooperação: o desejo de ver a sua pesquisa transformada em produto, para que a sociedade possa ter acesso a ele; e a possibilidade imediata de sua unidade desenvolver tecnologia de produto aplicável ao setor de EMHO, desde que 1) não seja necessária a realização de modificações nas competências de pesquisa dela, 2) assim como na reorganização das atividades que ela desenvolve.

Para exemplificar a segunda razão supracitada, cita-se o caso do Departamento de Física e Matemática [DFM]. O DFM possui as competências para o desenvolvimento de tecnologias aplicáveis ao setor em questão - fato que parece não se observar tão explicitamente no Departamento de Medicina Social, por exemplo. O DFM também não possui, aparentemente, atividades de extensão que consumam tanto o tempo de trabalho dos seus docentes, como acontece com o Departamento de Cirurgia e Anatomia, onde os professores realizam cirurgias, atividade que toma grande parte da sua carga laboral e os impossibilita de executar pesquisas que visem ao desenvolvimento de tecnologias. 
Assim, pelo fato de o DFM priorizar a pesquisa e já ter as competências instaladas para tal, ele tem mais subsídios para a realização de projetos cooperativos com as empresas, especialmente no que se refere à transferência de tecnologia.

\section{O Papel das Empresas}

Apesar da clara necessidade de ajuste da universidade para que a cooperação com as empresas aconteça, o setor empresarial analisado também deve modificar sua postura, totalmente reativa no momento, a qual demonstra que os empresários esperam que a universidade faça todo o trabalho de criação das condições ideais para que haja a interação dessas partes.

Enfatiza-se a necessidade de as empresas serem mais atuantes no processo de cooperação com a universidade, como, por exemplo, no apontamento de profissionais para a realização de prospecções nos laboratórios da academia, pois foi detectado que elas não tinham o menor conhecimento do que era produzido dentro das unidades universitárias pesquisadas.

As empresas deveriam propor ações conjuntas com a universidade, buscando uma melhoria dos processos que geram a cooperação entre essas entidades. Tais ações seriam também a resposta à necessidade de um novo posicionamento dessas organizações pertencentes ao primeiro setor, em um momento no qual tanto se discute a responsabilidade socioempresarial [RSE]. Essa proposição repousa no fato de que uma das premissas da RSE é a necessidade de o setor empresarial influenciar positivamente as políticas do setor público - no caso, a universidade - pois tais ações tendem a ser revertidas de forma favorável a toda a sociedade, gerando satisfação às partes interessadas no objeto da parceria.

Ademais, as empresas precisam compreender as normas existentes na universidade, especialmente no que toca à questão do patenteamento, para que não haja dissensões desnecessárias a respeito do assunto, como pode ser observando no momento em que um executivo se posicionou radicalmente contra a divisão da patente de uma tecnologia originada na universidade; tal fato não pode ser admitido, já que todo invento realizado no âmbito da Universidade de São Paulo tem essa instituição com proprietária, individualmente ou de forma compartilhada.

\section{CONCLUSÃO}

Apesar de vários ajustes que necessitam ser realizados, tanto por parte da universidade quanto pelo setor empresarial, acredita-se que exista ampla possibilidade de transferência de tecnologia das unidades universitárias analisadas para as empresas do setor de EMHO. Essa questão pode ser tanto observada pelo prisma do conhecimento daquelas pessoas envolvidas no processo, como por suas convicções pessoais.

Com relação ao saber, deve ser destacada a capacidade que a universidade tem de produzir conhecimento passível de ser aplicável ao setor de EMHO. Para evidenciar a existência desse conhecimento, vale destacar que as unidades universitárias pesquisadas dispõem de vasto repertório de competências que interessam ao referido setor, como se pode observar no resultado das entrevistas com as empresas: vinte e quatro competências, provenientes das três unidades pesquisadas, foram apontadas como potencialmente interessante para elas.

Tais competências possibilitam que a universidade desenvolva as mais variadas tecnologias aplicáveis a essa indústria, fato que também é propiciado pela considerável estrutura de que ela dispõe, como fica evidenciado na demonstração da quantidade de laboratórios que cada unidade possui. 
Além disso, devem ser ressaltados como exemplos dessa potencialidade as trinta tecnologias já desenvolvidas (ou em desenvolvimento) pela universidade para o setor em questão; dessas, treze já foram patenteadas, ou tiveram o pedido já depositado.

Pode-se argumentar que tais tecnologias - à exceção de uma - não interessaram às empresas pesquisadas e por isso elas não se constituiriam em um indicador consistente das possibilidades de transferência de tecnologia; contudo, apurou-se que tal fato se deu pela incompatibilidade das áreas de atuação das empresas pesquisadas (alocadas em partes específicas dos segmentos odontológicos, médico-hospitalar, laboratorial e de materiais de consumo) com as tecnologias desenvolvidas pela universidade, e não porque as tecnologias em questão não se aplicam ao mercado.

Apesar da verificação efetuada pelo pesquisador, junto aos entrevistados do setor empresarial, com relação à razão do baixo interesse com relação às tecnologias desenvolvidas pela universidade, o parágrafo anterior aponta a oportunidade de realização de futuras pesquisas. Deve-se investigar empresas de outros segmentos do setor de EMHO, ou de qualquer outro setor componente do complexo da saúde, para verificar se essa incompatibilidade se deve realmente a uma simples distinção de área de atuação, ou se algo mais pode ser identificado. Esses itens adicionais poderiam configurar uma incompatibilidade regional, incongruência entre os interesses da universidade e das empresas, ou até mesmo a incompetência da academia em produzir algo que possa ser realmente útil ao setor produtivo.

Outro componente dessa vertente do conhecimento repousa no quadro qualificado de pesquisadores de que dispõem as unidades universitárias analisadas, visto que todos os docentes entrevistados são no mínimo doutores e têm vasta gama de artigos científicos publicados, tanto no Brasil quanto no exterior. Também importa mencionar que alguns deles ainda inventaram e desenvolveram algumas tecnologias que se transformaram em patentes, fato que pode evidenciar o potencial tecnológico de suas habilidades.

Contudo, deve-se ressaltar que a maioria das patentes nunca resultou em inovação, ou seja, nunca foram comercializadas. Isso leva, mais uma vez, à suspeita de que as pesquisas universitárias não têm o direcionamento necessário para atender aos anseios do mercado, apesar de serem realizadas por pesquisadores reconhecidamente competentes em suas áreas de atuação, dados os seus títulos e publicações acadêmicas. As razões para tal devem ser investigadas em novas pesquisas, conforme anteriormente exposto.

No que concerne às convicções pessoais, deve-se salientar o desejo de uma grande parte dos docentes entrevistados de desenvolver atividades em cooperação com o setor empresarial, fato que gera a possibilidade da realização da transferência de tecnologia. A mesma percepção se observou nas entrevistas com os executivos, o que demonstra uma predisposição positiva de ambas as partes em buscarem a interação - apesar de haver algumas vozes dissonantes nos dois lados.

Todo esse potencial pode ser obstruído pela incapacidade gerencial que parece permear as entidades que regulam o funcionamento da universidade. $\mathrm{O}$ fato de o professor não ser recompensado devidamente por seus esforços relativos à cooperação com as empresas, assim como pela efetivação da transferência de tecnologias, torna-se um desmotivador sobremaneira relevante.

A regulamentação equivocada da avaliação docente ressalta também um problema de ordem operacional: os professores/pesquisadores não têm tempo suficiente para se dedicar, de forma apropriada, tanto àquelas atividades que lhes permitem ser adequadamente avaliados, quanto às atividades extras, categoria em que se encaixa a cooperação U-E e a transferência de tecnologia.

Importa questionar o porquê desta regulamentação tão míope, que não facilita a cooperação U-E e a transferência de tecnologia. Qual a causa dessa gestão equivocada? A falta de visão das benesses decorrentes dos processos supracitados? Ou seria uma barreira cultural, que idealiza a produção originada do setor público como sacra, pensamento possivelmente arraigado numa ética católica dominante no Brasil, que preconiza a miscigenação de entidades públicas com investimentos privados como uma fonte de mácula para a santidade estatal? 
É fato que as unidades acadêmicas pesquisadas desenvolvem tecnologias. Necessário se faz indagar qual é/será o destino dessas tecnologias, e por que assim ocorre. A pesquisa apontou dúvidas sobre a utilização comercial das tecnologias atualmente desenvolvidas nas unidades acadêmicas e no setor produtivo analisados. Todavia forneceu indicadores da existência de competências instaladas nas referidas unidades. Além disso, traçou-se um quadro de quão importante e decisiva é a ação da USP e dos órgãos reguladores das atividades docentes no direcionamento das atividades dos pesquisadores, o que impacta fortemente a realização ou não de transferência de tecnologia.

Posicionadas todas essas variáveis e stakeholders em um mesmo ambiente, tem-se um resultado imprevisível até o momento, o que, a priori, impede a resposta do questionamento título deste trabalho (E Agora, o que Fazer com Essa Tecnologia?). Argumenta-se que esta investigação apontou fatoreschave que interferem no processo de transferência de tecnologia da universidade para a empresa, os quais podem ser operacionalizados no sentido de maximizar o potencial desse processo, caso haja esforço conjunto de todas as partes envolvidas na ação.

\section{Artigo recebido em 02.10.2007. Aprovado em 12.08.2008.}

\section{NOTAS}

\footnotetext{
${ }^{1}$ Escola de Enfermagem de Ribeirão Preto.

${ }^{2}$ Faculdade de Ciências Farmacêuticas de Ribeirão Preto.

${ }^{3}$ Faculdade de Filosofia, Ciências e Letras de Ribeirão Preto.

${ }^{4}$ Faculdade de Medicina de Ribeirão Preto.

${ }^{5}$ Faculdade de Odontologia de Ribeirão Preto.
}

\section{REFERENCIAS BIBLIOGRÁFICAS}

Alvim, P. C. R. C. (1998). Cooperação universidade-empresa: da intenção à realidade. In Interação universidade empresa (pp. 99-125). Brasília: IBICT.

Anuário Estatístico. (2008a). Produção científica em periódicos e livros: número de trabalhos, número de participações e número de autores por unidade (Tabela 3.31). Recuperado em 30 maio, 2008, de http://sistemas.usp.br/anuario/tabelas/T03_31.pdf

Anuário Estatístico. (2008b). Produção científica em anais de congressos: número de trabalhos, número de participações e número de autores por unidade (Tabela 3.32). Recuperado em 30 maio, 2008, de http://sistemas.usp.br/anuario/tabelas/T03_32.pdf

Associação Brasileira da Indústria de Artigos e Equipamentos Médicos, Odontológicos, Hospitalares e de Laboratórios, \& Sindicato da Indústria de Artigos e Equipamentos Odontológicos, Médicos e Hospitalares do Estado de São Paulo. (2008). Dados econômicos. Recuperado em 30 maio, 2008, de http://www.abimo.org.br/abimo_sinaemo/dados_economicos/dados_economicos.asp

Chaimovich, H. (1999). Por uma relação mutuamente proveitos entre universidade de pesquisa e empresas. Revista de Administração da Universidade de São Paulo, 34(4), 18-22.

Classificação Nacional de Atividades Econômicas. (2004). Tabela CNAE. Recuperado em 19 setembro, 2004, de http://www.cnae.ibge.gov.br/cgi-bin/cnaeprd.dll/html/HieClasse?SEC=D\&DIV=33\&GRP=331\&CLA=33103\&TIPO=C100 
Etzkowitz, H., \& Leydesdorff, L. (1997a). Introduction: universities in the global knowledge economy. In H. Etzkowitz, \& L. Leydesdorff (Eds.). Universities and the global knowledge economy: a triple helix of university-industry-government relations (pp. 1-10). Londres: Continuum.

Etzkowitz, H., \& Leydesdorff, L. (1997b). A triple helix of university-industry-government relations. In H. Etzkowitz, \& L. Leydesdorff (Eds.). Universities and the global knowledge economy: a triple helix of university-industry-government relations (pp. 155-162). Londres: Continuum.

Fracasso, E., \& Santos, M. (1992). Modelos de transferência de tecnologia da universidade para a empresa. Perspectiva Econômica, 27(78), 57-66.

Francis, D., \& Bessant, J. (no prelo). Targeting innovation and implications for capability development. Technovation. Recuperado em 7 dezembro, 2004, de http://www.sciencedirect.com/science?_ob=ArticleURL\&_udi=B6V8B-4CDHHB1-

$1 \& \_u s e r=687303 \&$ coverDate $=03 \% 2 \mathrm{~F} 31 \% 2 \mathrm{~F} 2005 \& \_$rdoc $=2 \&$ fmt $=$ high $\&$ orig=browse\&_src $\mathrm{h}=\mathrm{doc}-$

info(\%23toc\%235866\%232005\%23999749996\%23549348\%23FLA\%23display\%23Volume)\& _cdi $=5866 \& \_s o r t=d \&$ docanchor $=\&$ view $=\mathrm{c} \&$ _ct $=14 \&$ acct $=$ C000037779\&_version $=1 \&$ _urlV ersion $=0 \& \_u s e r i d=687303 \& \mathrm{md} 5=07 \mathrm{c} 3 \mathrm{fd} 957 \mathrm{a} 329 \mathrm{df} 6976 \mathrm{ba} 41$ eaacf $87 \mathrm{~d} 6$

Frost \& Sullivan. (2005). Recuperado em 8 abril, 2005, de http://www.frost.com/prod/servlet/vpfurther-info.pag? mode $=$ open $\&$ sid $=2850206$

Gutierrez, R. M. V., \& Alexandre, P. V. M. (2004). Complexo industrial da saúde: uma introdução ao setor de insumos e equipamentos de uso médico. BNDES Setorial, (19), 119-155.

Instituto Brasileiro de Geografia e Estatística. (2002). Pesquisa industrial de inovação tecnológica 2000. Rio de Janeiro: Autor.

Instituto Brasileiro de Geografia e Estatística. (2007). PIA - Pesquisa industrial empresa 2005 (Vol. 24, Núm.1). Rio de Janeiro: Autor.

Jain, R. K., \& Triandis, H. C. (1997). Management of research and development organizations: managing the unmanageable (4a ed.). Nova York: Wiley-Interscience.

Marques, F. (2007). No clube dos 200: USP e Unicamp galgam posições em ranking mundial de universidades. Pesquisa Fapesp Online. Recuperado em 2 junho, 2008, de http://www.revistapesquisa.fapesp.br/?art=3400\&bd=1\&pg=1\&lg=

Metcalfe, J. S. (2003). Equilibrium and evolutionary foundations of competition and technology policy: new perspectives on the division of labour and the innovation process. Revista Brasileira de Inovação, 2(1), 111-146.

Ministério do Trabalho e Emprego. (2008). RAIS 2005 - Relatório anual de informações sociais. $\begin{array}{lllll}\text { Recuperado } & 27 & \text { maio, }\end{array}$ http://www.mte.gov.br/EstudiososPesquisadores/PDET/Acesso/RaisOnLine.asp.

Mora-Valentin, E. M., Montoro-Sanchez, A., \& Guerra-Martin, L. A. (2004). Determinig factors in the success of R\&D cooperative agreements between firms and research organizations. Research Policy, 33(1), 17-40.

Natal, Y. D., \& Vivés, A. (1998). Gerenciamento do processo de transferência de tecnologia. Anais do Simpósio de Gestão da Inovação Tecnológica, São Paulo, SP, Brasil, 20.

Nuchera, A. H., Serrano, G. L., \& Morote, J. P. (2002). La gestión de la innovación y la tecnología en las organizaciones. Madrid: Ediciones Pirámide. 
Organização para Cooperação e Desenvolvimento Econômico. (2004). Science, technology and industry outlook - 2002 (Highlights). Recuperado em 14 abril, 2004, de http://www.oecd.org/dataoecd/61/31/2762979.pdf

Plonski, G. A (1992). Prefácio a la cooperación empresa-universidad en Iberoamerica. In Cooperación empresa-universidad en Iberoamerica (pp. VII-XIV). São Paulo: CYTED.

Plonski, G. A. (1998). Cooperação empresa-universidade no Brasil: um novo balanço prospectivo. In A. G. Plonski (Coord.). Interação universidade-empresa (Vol. 1, pp. 09-23). Brasília: IBICT.

Plonski, G. A. (1999). Cooperação universidade-empresa: um desafio gerencial complexo. Revista de Administração da Universidade de São Paulo, 34(4), 5-12.

Porto, G. (2000). A decisão empresarial de desenvolvimento tecnológico por meio da cooperação empresa-universidade. Tese de doutorado, Universidade de São Paulo, São Paulo, SP, Brasil.

Porto, G. (2004). Pré-projeto do parque tecnológico no campus da USP de Ribeirão Preto (versão preliminar). (Relatório de pesquisa). FEARP-USP, Ribeirão Preto, SP, Brasil.

Porto, G. (2006). A decisão de cooperação universidade - empresa sob a ótica dos líderes de grupos de pesquisa da USP cadastrados no diretório de pesquisa do CNPq. Tese de livre docência, Universidade de São Paulo, São Paulo, SP, Brasil.

Reisman, A. (2004). Transfer of technologies: a cross-disciplinary taxonomy. The International Journal of Management Science, 33(3), 189-202.

Richardson, R. J., \& colaboradores. (1999). Pesquisa social: métodos e técnicas. São Paulo: Atlas.

Rogers, E. M., Takegami, S., \& Yin, J. (2001). Lessons learned about technology transfer. Technovation, 21(4), 253-261.

Santoro, M. D., \& Betts, S. C. (2002). Making industry-university partnerships work. Research Technology Management, 45(3), 42-46.

Santoro, M. D., \& Chakrabarti, A. K. (2002). Firm size and technology centrality in industryuniversity interactions. Research Policy, 31(7), 1163-1180.

Segatto, A. P. (1996). Análise do processo de cooperação tecnológica universidade-empresa: um estudo exploratório. Dissertação de mestrado, Universidade de São Paulo, São Paulo, SP, Brasil.

Segatto-Mendes, A. P., \& Sbragia, R. (2002). O Processo de cooperação universidade-empresa em universidades brasileiras. Revista de Administração da Universidade de São Paulo, 37(4), 5871.

Siegel, D. S., Waldman, D. A., \& Link, A. N. (2003). Assessing the impact of organizational practices on the relative productivity of university technology transfer offices: an exploratory study. Research Policy, 32(1), 27-48.

Siegel, D. S., Waldman, D. A., Atwater, L. E., \& Link, A. N. (2003). Commercial knowledge transfers from universities to firms: improving the effectiveness of university-industry collaboration. Journal of High Technology Management Research, 14(1), 111-133.

Vedovello, C. (1998). Firms' R \& D activity and intensity and university-enterprise partnerships. Technological Forecasting and Social Change, 58(3), 215-226. 
E Agora, o que Fazer com Essa Tecnologia? Um Estudo Multicaso sobre as Possibilidades de

Transferência de Tecnologia na USP-RP

World Intellectual Property Organization. (n.d). What is intellectual property? Recuperado em 21 janeiro, 2005, de http://www.wipo.int/about-ip/en/

Yin, R. K. (2001). Estudo de caso: planejamento e métodos (2a ed.). Porto Alegre: Bookman. 